\title{
ASSESSMENT OF LEFT VENTRICULAR SYSTOLIC FUNCTION AFFECTION IN PATIENTS WITH FREQUENT PREMATURE VENTRICULAR COMPLEXES BY REAL-TIME THREE- DIMENSIONAL SPECKLE TRACKING ECHOCARDIOGRAPHY
}

By

\author{
Ahmed El-Sebae Kasem**, Abd El-Mohsen M. Aboualia*, Taher Said \\ Abd El-Kareem**, and *Mohamed Samy Abd El-Samie \\ *Cardiology Department, Faculty of Medicine and **Islamic Cardiac Center of cardiology, \\ Al-Azhar University, Cairo, Egypt \\ **Corresponding author: Ahmed El-Sebae Kasem,
}

Mobile: 01069201315, E-mail: dr.kasem91@ gmail.com

\begin{abstract}
Background: Premature ventricular contractions have been described in $1 \%$ of clinically normal people as detected by standard ECG and 40-75\% of apparently healthy persons as detected by 24-48 hour ambulatory ECG recording (Holter). In the absence of structural heart diseases, it is thought to be relatively benign. However, PVC-induced cardiomyopathy has been a subject of great interest over the last decade.

Objective: To evaluate subtle and early premature ventricular complex (PVC)-induced ventricular impairment in patients with frequent PVCs and without structural heart disease by real-time 3-dimensional speckle tracking echocardiography (RT3D-STE).

Patients and Methods: Forty patients were included in this study with asymptomatic frequent PVCs. Patients without structural heart disease was excluded. Detailed history, physical examination, full laboratory investigations, resting ECG, 24 hours Holter monitoring, conventional 2D echocardiography assessment of left ventricular ejection fraction (LVEF), strain imaging with measurement of LV-GLS, 2D speckle tracking and RT3D-STE (global longitudinal, area, radial, and circumferential strain (GLS, GAS, GRS, and GCS)). The study was performed at Islamic Cardiac Centre of Cardiology, Al-Azhar University during the period from September 2019 to April 2020.
\end{abstract}

Results: RT3D-STE modalities detectap early subtle LV dysfunction better than conventional echocardiographic and showed a significant correlation with PVCs burden, origin, focality, interpolated PVCs and duration of the complex of ectopic beat.

Conclusion: Frequent premature ventricular complexes could produce LV dysfunction and cardiomyopathy independently of any pre-existing underlying structure heart disease and early detection of subtle LV dysfunction can be done by RT3D-STE modalities even in asymptomatic patient.

Keywords: Premature Ventricular Complexes, Echocardiography, Real-Time 3-Dimensional Speckle Tacking echocardiography, Left Ventricular Function. 


\section{INTRODUCTION}

Ventricular premature beats (VPBs), premature ventricular complexes/ contractions (PVCs), or ventricular extra systole is ectopic beats that arise from within the ventricles. They are common and can occur in a wide variety of clinical scenarios and in a diverse population. Patients present either without symptoms, acutely symptomatic due to PVCs themselves, or with progressive symptoms from the cumulative effects that frequent PVCs can have on myocardial contractility (Koester et al., 2020).

Premature ventricular complexes (PVCs) are among the most common cardiac arrhythmias encountered in clinical practice. There has been a recent accumulation of evidence implicating PVCs as a cause of reversible cardiomyopathy (Del Carpio Munoz et al., 2011).

Although frequent PVCs are a wellrecognized potential cause of reversible cardiomyopathy, underlying mechanisms remain poorly understood. Postulated mechanisms include electrical dyssynchrony, similar to that of left bundle branch block or pacing-induced left ventricular dyssynchrony, abnormal calcium handling from short-coupled PVCs, or abnormal filling with postectopic pauses (Panizo et al., 2011).

However, there appear to be differences in susceptibility to development of cardiomyopathy. Reversible PVCs associated cardiomyopathy may occur at lower PVC burden (e.g., < 4-10,000) while some with very high burden maintain normal ventricular function (Gorenek et al., 2019).
Assessment of LVEF may be carried out by either conventional echocardiogram or by speckle tracking strain imaging and several studies emerged over last five years reporting the use of speckle tracking strain imaging to detect subtle changes in the ventricles (Yokokawa et al., 2012).

Traditional echocardiographic methods may not effectively evaluate subtle and early forms of PVC-induced ventricular function impairment. Real-time 3dimensional (3D) speckle tracking echocardiography (STE), an advancement over conventional 2-dimensional (2D) STE, provides a new, convenient and noninvasive method for quantitative evaluation of cardiac function by allowing to measure strain values, better capturing 3D cardiac motion and addressing the failure of 2D-STE to track out-of-plane speckle motion (D'Ascenzi et al., 2016).

Three-dimensional speckle-tracking has been implemented for measuring 3D strain, and has emerged as a more physiologically sound tool for analyzing the complexity of LV mechanics, overcoming the inherent limitations of 2D-STE. Due to the superiority provided by the addition of the third dimension for myocardial deformation analysis (e.g., no through-plane motion of speckles, ability of tracking the speckles in two directions simultaneously for area strain quantification, etc.), 3D-STE has the potential to become the gold-standard technique for assessing LV systolic function by echocardiography in the near future (Muraru et al., 2018).

The aim of this work wes to assess feasibility of real-time three-dimensional speckle tracking echocardiography for early detection of subtle left ventricular 
systolic dysfunction in patients with frequent premature ventricular complexes without structural heart disease, detection of risk factor and frequency of PVCs associated with PVCs induced cardiomyopathy which might be useful for early detection and risk stratification of cardiac function impairment and to consider PVC inhibiting treatment if appropriate.

\section{PATIENTS AND METHODS}

This pilot study involved patients with premature ventricular complexes collected from the Cardiology clinic of Al-Azhar University Hospitals. The patients were screened for the study enrolment prospectively. The study was performed at Islamic Cardiac Centre of Cardiology, AlAzhar University during the period from September 2019 to April 2020.

The protocol and all corresponding documents were approved by Ethical and Research committee, Faculty of Medicine, Al-Azhar University and patients provided informed consents.

The patients were classified into two groups matched in age:

Group (1): Patients' group: 40 patients with frequent premature ventricular complexes.

Group (2): Control group: 20 volunteers (22-60 years old) with similar demographic characteristics but without VESs were included as the control group.

A. Inclusion criteria: Asymptomatic frequent PVCs without structural heart disease and normal conventional echocardiographic examination.

B. Exclusion criteria: Patients with impaired systolic function $(\mathrm{EF}<50 \%$, patients with a significant valvular heart disease, myocardial diseases and pericardial disease, congenital heart disease, history suggestive of ischemic heart disease, left ventricular hypertrophy, uncontrolled hypertensive patients, diabetic patients using insulin, patients with a history of atrial fibrillation or cardiomyopathies, patients with chronic systemic or inflammatory diseases and any form of malignancy.

All subjects were exposed to full history taking, general and local cardiac examination, resting 12-lead ECG, 24hour Holter monitoring: (Lown et al., 1969), Resting conventional TransThoracic Echocardiography: (Lang and Roberto, 2015) and (Nagueh and Man., 2016), 2D Speckle Tracking Echocardiography: (Gorcsan and Tanaka, 2014), RT3D-STE Speckle Tracking Echocardiography: (Galderisi et al., 2012).

\section{Statistical analysis:}

Data were tabulated and analysed using the computer program SPSS (Statistical package for the social science) version 20.0 (SPSS Inc., Chicago, Illinois, USA). Quantitative data were expressed as mean standard deviation (SD), range Qualitative data were expressed as frequency and parentage.

The following tests were done: independent-samples t-test of significance: was used when comparing between two means.

One-way ANOVA with post hoc test: Last Significant Difference (LSD) was used for multiple comparisons, Pearson correlation Coefficient. 
Probability (P-value) P-value $<0.05$ was considered significant. Receiver operating characteristics (ROC) curves were used to detect cut-off point, sensitivity, specificity, positive predictive value (PPV) and negative predictive value (NPV).

\section{RESULTS}

The study included: 18 males and 22 females, the mean age was $(39.93 \pm 10.59)$ years, age ranged from 18years to 59 years.

There was no statistically significant difference $(\mathrm{P}$-value $>0.05)$ between the patients and control as regarding risk factors, patients were $32.5 \%$ hypertensive, $17.5 \%$ diabetic, $22.5 \%$ smokers and $15 \%$ have positive family history, while control were $25 \%$ hypertensive, $25 \%$ diabetic and $20 \%$ smokers, $15 \%$ have positive family history of cardiovascular disease.

In our study we classified PVCs according to their origin depending on ECG: 5 patients (12.5\%) had PVCs of LV origin, $8(20.0 \%)$ had PVCs of LVOT origin, $5(12.5 \%)$ had PVCs of Multifocal origins, $5(12.5 \%) \%$ ) had PVCs of RV origin, $17(42.5 \%)$ had PVCs of RVOT origin in order to assess the relation between PVCs origin and LV dysfunction, we found that there is statistically significant correlation between origin of PVCs with 2D speckle LV GLS, 3D speckle tracking LV GLS and 3D LV GAS.

As regard comparison between patients and control groups using conventional echocardiography there were no statistically significant difference as (Table 1).

Table (1): Comparison between patients and control according to conventional echocardiography

\begin{tabular}{|c|c|c|c|c|}
\hline \multicolumn{2}{|c|}{$\begin{array}{ll}\text { Echocardiography } & \text { Groups }\end{array}$} & $\begin{array}{c}\text { Patient } \\
(n=40)\end{array}$ & $\begin{array}{c}\text { Control } \\
(\mathbf{n}=\mathbf{2 0})\end{array}$ & p-value \\
\hline \multirow{2}{*}{ LAD (mm) } & Mean \pm SD & $35.28 \pm 4.90$ & $33.25 \pm 3.75$ & \multirow{2}{*}{$>0.05$} \\
\hline & Range & $27-56$ & $25-41$ & \\
\hline \multirow{2}{*}{ LV EDD (mm) } & Mean \pm SD & $48.62 \pm 3.83$ & $46.83 \pm 3.35$ & \multirow{2}{*}{$>0.05$} \\
\hline & Range & $40-57$ & $40-53.2$ & \\
\hline \multirow{2}{*}{ LV ESD (mm) } & Mean \pm SD & $30.42 \pm 3.88$ & $28.81 \pm 3.75$ & \multirow{2}{*}{$>0.05$} \\
\hline & Range & $23-39$ & $23.2-36$ & \\
\hline \multirow{2}{*}{ LV EDV (ml) } & Mean \pm SD & $116.53 \pm 23.62$ & $111.85 \pm 15.06$ & \multirow{2}{*}{$>0.05$} \\
\hline & Range & $70-158$ & 79-136 & \\
\hline \multirow{2}{*}{ LV ESV (ml) } & Mean \pm SD & $42.00 \pm 13.86$ & $39.08 \pm 8.66$ & \multirow{2}{*}{$>0.05$} \\
\hline & Range & $18.5-63$ & $25-54$ & \\
\hline \multirow{2}{*}{ LV EF\% } & Mean \pm SD & $65.28 \pm 7.59$ & $67.81 \pm 7.25$ & \multirow{2}{*}{$>0.05$} \\
\hline & Range & $55.2-82.1$ & $59-79.5$ & \\
\hline
\end{tabular}

In comparison between patients and control using 2D speckle tracking echocardiography we found highly statistically significant difference between groups according to 2D speckle tracking echocardiography (LV GLS) (Table 2). 
Table (2): Comparison between patients and control according to 2D STE (LV GLS)

\begin{tabular}{|c|c|c|c|}
\hline 2D-STE LV GLS Groups & $\begin{array}{c}\text { Patients } \\
(n=40)\end{array}$ & $\begin{array}{c}\text { Control } \\
(\mathbf{n}=\mathbf{2 0})\end{array}$ & p-value \\
\hline Mean \pm SD & $-17.68 \pm 3.47$ & $-22.15 \pm 1.66$ & \multirow{2}{*}{$<0.001$} \\
\hline Range & $-23--10$ & $-25-20$ & \\
\hline
\end{tabular}

The study revealed highly statistically significant difference between patients and control groups according to 3D speckle tacking strain values (LV GLS,
LV GAS, LV GRS and LV GCS) and no statistical significance in LV EF (Table 3).

Table (3): Comparison between patients and control according to 3D echocardiography

\begin{tabular}{|c|c|c|c|c|}
\hline \multicolumn{2}{|c|}{ 3D Echocardiography Groups } & $\begin{array}{c}\begin{array}{c}\text { Patient } \\
(n=40)\end{array} \\
\end{array}$ & $\begin{array}{c}\text { Control } \\
(\mathbf{n}=\mathbf{2 0})\end{array}$ & p-value \\
\hline \multirow{2}{*}{ LV EF\% } & Mean \pm SD & $63.33 \pm 6.46$ & $65.90 \pm 5.04$ & \multirow{2}{*}{$>0.05$} \\
\hline & Range & 53_79 & 59_75 & \\
\hline \multirow{2}{*}{ LV GLS\% } & Mean \pm SD & $-16.53 \pm 3.66$ & $-21.25 \pm 1.29$ & \multirow{2}{*}{$<0.001$} \\
\hline & Range & $-21 \_-11$ & $-24 \_-20$ & \\
\hline \multirow{2}{*}{ LV GAS\% } & Mean \pm SD & $-26.78 \pm 4.13$ & $-31.80 \pm 1.40$ & \multirow{2}{*}{$<0.001$} \\
\hline & Range & $-33 \_-18$ & $-35-30$ & \\
\hline \multirow{2}{*}{ LV GRS\% } & Mean \pm SD & $33.13 \pm 4.60$ & $42.95 \pm 2.33$ & \multirow{2}{*}{$<0.001$} \\
\hline & Range & 27_41 & 40_48 & \\
\hline \multirow{2}{*}{ LV GCS\% } & Mean \pm SD & $-16.33 \pm 2.48$ & $-20.60 \pm 1.73$ & \multirow{2}{*}{$<0.001$} \\
\hline & Range & $-21-11$ & $-24-18$ & \\
\hline
\end{tabular}

As regard the PVCs Origin and speckle tracking there was statistically significant relation between $\mathrm{PVCs}$ origin and $2 \mathrm{D}$ speckle LV GLS, 3D LV GLS and 3D LV GAS in patients group as shown in Table (4).

Table (4): Relation between origin of PVCs detected by 2D speckle LV GLS, 3D LV GLS and 3D LV GAS in patients group

\begin{tabular}{|c|c|c|c|c|c|c|c|}
\hline \multicolumn{2}{|c|}{ Origin of PVCs } & LV & Multifocal & RV & LVOT & RVOT & \multirow{2}{*}{ p-value } \\
\cline { 1 - 9 } Speckle Tracking & & & & & & & \\
\multirow{2}{*}{ 2D LV GLS } & Mean & -18.60 & -13.60 & -20.40 & -19.38 & -17.00 & \multirow{2}{*}{$<0.001$} \\
\cline { 2 - 9 } & \pm SD & 2.70 & 2.88 & 2.51 & 2.00 & 3.54 & \\
\hline \multirow{2}{*}{ 3D LV GLS } & Mean & -17.20 & -13.40 & -20.40 & -16.75 & -16.00 & \multirow{2}{*}{$<0.001$} \\
\cline { 2 - 8 } & \pm SD & 3.77 & 2.61 & 0.55 & 3.06 & 3.87 & \\
\hline \multirow{2}{*}{ 3D LV GAS } & Mean & -27.60 & -23.00 & -30.20 & -27.13 & -26.47 & \multirow{2}{*}{$<0.001$} \\
\cline { 2 - 8 } & \pm SD & 4.28 & 4.53 & 0.45 & 4.29 & 3.91 & \\
\hline
\end{tabular}

As regard PVCS characteristics in our patient in $24 \mathrm{~h}$ Holter the mean of average heart rate by $24 \mathrm{~h}$ Holter $75.08 \pm 7.01 \mathrm{~b} / \mathrm{m}$, and Coupling interval $499.07 \pm 43.99 \mathrm{msec}$, mean of Burden\% 14.84 \pm 4.80 , Runs (12.5\%), PVCs duration: Mean \pm SD
138.25 $\pm 8.80 \mathrm{msec}$, ST deviation $(0 \%)$ and interpolated PVCs 6\%.

There was no statistically significant correlation between average heart rate in 24 hours Holter and coupling interval of PVCs with 2D or 3D speckle tracking echocardiography, on the other hand there 
were strong correlation between PVCs duration with 2D-STE GLS and RT-3D STE strain values GLS, GAS, GRS and GCS (p-value $<0.05)$.
As regard PVCs burden and speckle tracking echocardiography strain values we found strong correlation between PVCs burden and global strain values by 2D and 3D speckle tracking (Table 5).

Table (5): Correlation between Burden with echocardiography 2D and 3D, Speckle tracking echocardiography using Pearson correlation Coefficient in patients group

\begin{tabular}{|c|c|c|c|}
\hline \multicolumn{3}{|c|}{ Speckle Tracking Echocardiography } & Burden \\
\hline \multirow{2}{*}{ 2D speckle tracking } & \multirow{2}{*}{ LV GLS\% } & $\mathrm{r}$ & 0.758 \\
\cline { 3 - 4 } & & $\mathrm{p}$-value & $<0.001$ \\
\hline \multirow{4}{*}{ LV GLS\% } & $\mathrm{r}$ & 0.777 \\
\cline { 3 - 4 } & & $\mathrm{p}$-value & $<0.001$ \\
\cline { 3 - 4 } 3D speckle tracking & \multirow{2}{*}{ LV GAS\% } & $\mathrm{r}$ & 0.716 \\
\cline { 3 - 4 } & \multirow{2}{*}{ LV GRS $\%$} & $\mathrm{p}$-value & $<0.001$ \\
\cline { 3 - 4 } & & $\mathrm{r}$ & -0.676 \\
\cline { 3 - 4 } & \multirow{2}{*}{ LV GCS $\%$} & $\mathrm{r}$ & $<0.001$ \\
\cline { 3 - 4 } & & $\mathrm{p}$-value & $<0.256$ \\
\hline
\end{tabular}

To find cut-off value of PVCs burden in which subtle LV dysfunction could occur by using both 2D and RT-3D

Table (6): Receiver-operating characteristic (ROC) curve for prediction of left ventricular systolic dysfunction using the echocardiography

\begin{tabular}{|c|c|c|c|c|c|c|}
\hline Speckle tracking & $\begin{array}{c}\text { Cut-off } \\
\text { Burden }\end{array}$ & Sen. & Spe. & PPV & NPV & AUC \\
\hline 2D: LV GLS\% (-20) & $\mathbf{1 3 . 5 \%}$ & $86.4 \%$ & $67.3 \%$ & $67.2 \%$ & $85.9 \%$ & 0.876 \\
\hline 3D: LV GLS\% (-19) & $\mathbf{1 4 . 5 \%}$ & $81.8 \%$ & $88.9 \%$ & $90 \%$ & $80 \%$ & 0.924 \\
\hline 3D: LV GAS\% (-29) & $\mathbf{1 4 . 5 \%}$ & $81 \%$ & $84.2 \%$ & $85 \%$ & $80 \%$ & 0.885 \\
\hline 3D: LV GRS\% (45) & $\mathbf{1 2 \%}$ & $79.4 \%$ & $83.3 \%$ & $96.4 \%$ & $61.7 \%$ & 0.857 \\
\hline 3D: LV GCS\% (-25) & $\mathbf{1 1 \%}$ & $80 \%$ & $60 \%$ & $93.3 \%$ & $53 \%$ & 0.600 \\
\hline
\end{tabular}

\section{DISCUSSION}

In the present study regarding 2D conventional echocardiographic parameters, there was no significant difference between case and control groups in mean LV-EF, LVEDD, LVESD, LVEDV, LVESV, and LAD. These findings coincided with Wijnmaalen et al. (2010) who found that no statistically difference between the PVCs group and control group regarding conventional 2D echocardiography.
Speckle Tracking echocardiography we use receiver operating characteristic curve (ROC curve) (Table 6). 
case and control groups. This indicates that PVCs may induce early LV dysfunction not detected by conventional 2D echocardiography measurements and this finding coincided with those of Wijnmaalen et al. (2010) and Lie et al. (2017). An important factor in in affection of LV systolic function is PVCs burden in our study all case group patients had PVCs with total PVCs number (PVCs burden) ranging between $6-29.4 \%$ of total beats. This correlation was strong positive for 2D speckle tracking LV-GLS. These finding coincided with those of $\mathrm{Del}$ Carpio Munoz et al. (2011). That correlation also found in RT-3D speckle tracking strain values (LV-GLS, LV-GAS, LV-GRS, and LV-GCS) that is compatible with Ling et al. (2019) who showed that the frequency of PVCs correlates at least modestly with the extent of LV dysfunction.

Studies have shown that LV systolic dysfunction can be seen even in patients with a significantly lower PVCs burden Dukes et al. (2015). An absolute cut-off point at which PVCs have a definitive adverse long-term outcome is yet to be definitively identified. However, one of the more frequently cited studies suggests that a PVC burden of $>24 \%$ has a sensitivity of $79 \%$ and specificity of $78 \%$ in predicting which patients will go on to develop PVC-induced cardiomyopathy Baman et al. (2010). In the study of Ling et al. (2019) compared patients with different PVC loads using $20 \%$ as a cut off, and found that those with higher PVC loads lower LVEF and strain values by RT-3D speckle tracking echocardiography.
In our study, by ROC analyses using RT 3D STE and 2D STE we found that, a $\%$ PVCs burden $14.5 \%$ optimally detected patients with a 3D: LV GLS less than $19 \%$, with a sensitivity of $81.8 \%$ and specificity of $88.9 \%$, and an area under the curve (AUC) of 0.924.A \%PVCs burden $14.5 \%$ optimally detected patients with a 3D: LV GAS less than $-29 \%$, with a sensitivity of $81 \%$ and specificity of $84.2 \%$, and an area under the curve (AUC) of 0.885 . A \%PVCs burden $12 \%$ optimally detected patients with a 3D: LV GRS less than $45 \%$, with a sensitivity of $79.4 \%$ and specificity of $83.3 \%$, and an area under the curve (AUC) of 0.857.A \%PVCs burden $11 \%$ optimally detected patients with a 3D: LV GCS less than $25 \%$, with a sensitivity of $80 \%$ and specificity of $60 \%$, and an area under the curve (AUC) of 0.600. A \%PVCs burden $12.5 \%$ optimally detected patients with a 2D: LV GLS less than $-18 \%$, with a sensitivity of $90.9 \%$ and specificity of $55.6 \%$, and an area under the curve (AUC) of 0.876 .

There was a strong significant correlation between higher PVC burden and worse both RT 3D STE and 2D STE strain but there was no significant correlation between PVC burden and LVEF. In the study of Cha et al. (2012). Although burden was significant, it was not the only factor contributing to impairment of LV systolic function. According to PVCs origin patients with PVCs were classified into 4 subgroups (RVOT, LVOT, LV and RV). In our study there were no significant differences were seen in LV-EF, LVEDD, LVESD, LVEDV and LV-ESV between the groups but we noticed that PVCs originating from the RVOT were associated with more LV 
dysfunction by decrease strain in both RT3D STE GLS, GAS and 2D-STE GLS. These findings are similar to findings of Bozkurt et al. (2016) which concluded that PVCs originating from the RVOT were the primary culprit for PVC-induced cardiomyopathy. As regard QRS duration we noticed insignificant statistical correlation between duration of complex and LV-EF, but there was statistically significant correlation between duration of complex with RT-3D STE strain values (GLS, GAS, GRS, and GCS) and 2D STE GLS. These finding was in agreement with those of Yokokawa et al. (2012).

Patients with interpolated PVCs had slightly lower LV-EF in comparison to patients without interpolated PVCs, but this difference was statistically insignificant. However, regarding patients with interpolated PVCs had a statistically significant decrease in global LV strain values by $2 \mathrm{D}$ speckle tracking than patients without interpolated PVCs. These finding coincided with those of Olgun et al. (2011). This results although found by RT-3D STE GLS and GAS but no significant correlation with GRS and GCS.

When we compared patients with multifocal versus patients with unifocal PVCs regarding strain imaging parameters included in our study a more decrease occurred in LV longitudinal strain in patients with multifocal PVCs than of patients with unifocal PVCs and, these differences were statistically significant. These finding coincides with Wijnmaalen et al. (2010) and Del Carpio Munoz et al. (2011) who found that patients with reduced LVEF were more likely to have multiform PVCs. These results, although found comparing patients with multifocal versus patients with unifocal PVCs by RT-3D STE GLS, GAS, and GRS but no significant correlation with GCS. According to PVCs longer coupling interval here was more impairment of speckle tracking strain values but without statistical significance regarding 2D STE GLS and RT-3D STE GLS, GAS, GRS, and GCS. These results coincided with Voskoboinik et al. (2020) who found that there was more adverse remodelling with variable PVC coupling interval.

\section{CONCLUSION}

Premature ventricular complexes may produce subtle LV dysfunction and cardiomyopathy independently of any preexisting underlying cardiac disease and early detection of subtle LV dysfunction can be done by speckle tracking echocardiographic modalities (RT-3D STE and 2D STE) other than conventional echocardiographic measures in asymptomatic PVCs patients.

\section{REFERENCES}

1. Baman, T. S., Lange, D. C., Ilg, K. J., Gupta, S. K., Liu, T. Y., Alguire, C and Pelosi Jr, F. (2010): Relationship between burden of premature ventricular complexes and left ventricular function. Heart rhythm, 7(7): 865-869.

2. Bozkurt, B., Colvin, M., Cook, J., Cooper, L. T., Deswal, A., Fonarow, G. C., Francis, G.S., Lenihan, D., Lewis, E.F., McNamara, D.M. and Pahl, E. (2016): Current diagnostic and treatment strategies for specific dilated cardiomyopathies: a scientific statement from the American Heart Association. Circulation, 134(23): 579-646.

3. Cha, Y. M., Lee, G. K., Klarich, K. W and Grogan, M. (2012): Premature 
ventricular contraction-induced cardiomyopathy: a treatable condition. Circulation: Arrhythmia and Electrophysiology, 5(1): 229-236.

4. D’Ascenzi, F., Solari, M., Mazzolai, M., Cameli, M., Lisi, M., Andrei, V and Mondillo, S. (2016): Twodimensional and three-dimensional left ventricular deformation analysis: a study in competitive athletes. The International Journal of Cardiovascular Imaging, 32(12): 1697-1705.

5. Del Carpio Munoz, F., Syed, F. F., Noheria, A., Cha, Y. M., Friedman, P. A., Hammill, S. C and Asirvatham, S. J (2011): Characteristics of premature ventricular complexes as correlates of reduced left ventricular systolic function: Study of the burden, duration, coupling interval, morphology and site of origin of PVCs. Journal of) Cardiovascular Electrophysiology, 22(7): 791-798.

6. Dukes, J. W., Dewland, T. A., Vittinghoff, E., Mandyam, M. C., Heckbert, S. R., Siscovick, D. S., and Marcus, G. M. (2015): Ventricular ectopy as a predictor of heart failure and death. Journal of the American College of Cardiology, 66(2): 101-109.

7. Galderisi, M., Esposito, R., SchianoLomoriello, V., Santoro, A., Ippolito, R., Schiattarella, P., Strazzullo, P. and De Simone, G. (2012): Correlates of global area strain in native hypertensive patients: a three-dimensional speckletracking echocardiography study. European Heart Journal-Cardiovascular Imaging, 13(9): 730-738.

8. Gorcsan J and Tanaka H (2014): Echocardiographic assessment of myocardial strain. Journal of the American College of Cardiology, 58(14): 1401-1413.

9. Gorenek, B., Fisher, J. D., Kudaiberdieva, G., Baranchuk, A.,
Burri, H., Campbell, K. B and Krishnan, K. (2019): Premature ventricular complexes: diagnostic and therapeutic considerations in clinical practice. Journal of Interventional Cardiac Electrophysiology, 1-22.

10. Koester, C., Ibrahim, A. M., Cancel, M., and Labedi, M. R. (2020): The Ubiquitous Premature Ventricular Complex. Cureus, 12(1): 2-6.

11. Lang $A$ and Roberto $M$ (2015): Recommendations for cardiac chamber quantification by echocardiography in adults: an update from the American Society of Echocardiography and the European Association of Cardiovascular Imaging. Journal of the American Society of Echocardiography, 28(1): 139.

12. Lie, Ø. H., Saberniak, J., Dejgaard, L. A., Stokke, M. K., Hegbom, F., Anfinsen, O. G. and Haugaa, K. H. (2017): Lower than expected burden of premature ventricular contractions impairs myocardial function. ESC heart failure, 4(4): 585-594.

13. Ling, Y., Wan, Q., Chen, $Q$ and Zhu, W. (2019): Assessment of subtle cardiac dysfunction in patients with frequent premature ventricular complexes by real time threedimensional speckle tracking echocardiography. Clinical Cardiology, 40(8), 554-558.

14. Lown B, Fakhro M, Hood B and Thorn W (1969): The coronary care unit. New perspectives and directions. Jam. Med. Assoc., 199:188-198.

15. Muraru, D., Niero, A., RodriguezZanella, H., Cherata, D and Badano, L. (2018): Three-dimensional speckletracking echocardiography: benefits and limitations of integrating myocardial mechanics with three- 
dimensional imaging. Cardiovascular diagnosis and therapy, 8(1): 101-117.

16. Nagueh $S F$ and Han $F$ (2016): Recommendations for the evaluation of left ventricular diastolic function by echocardiography: an update from the American Society of Echocardiography and the European Association of Cardiovascular Imaging. European Journal of Echocardiography, 17(12): 1321-1360.

17. Olgun, H., Yokokawa, M., Baman, T., Kim, H. M., Armstrong, W., Good, E and Morady, F. (2011): The role of interpolation in PVC-induced cardiomyopathy. Heart rhythm, 8(7): 1046-1049.

18. Panizo, J. G., Barra, S., Mellor, G., Heck, P., and Agarwal, S. (2018): Premature ventricular complex-induced cardiomyopathy. Arrhythmia \& Electrophysiology Review, 7(2): 128134.
19. Voskoboinik, A., Hadjis, A., Alhede, C., Im, S. I., Park, H., Moss, J and Lee, R. (2020): Predictors of adverse outcome in patients with frequent premature ventricular complexes: The ABC-VT risk score. Heart Rhythm.

20. Wijnmaalen AP, Delgado V, Schalij MJ, van Huls van Taxis CF, Holman ER, Bax JJ and Zeppenfeld K (2010): Beneficial effects of catheter ablation on left ventricular and right ventricular function in patients with frequent premature ventricular contractions and preserved ejection fraction. Heart, 96 (16): 1275-1280.

21. Yokokawa M, Kim HM, Good E, Crawford T, Chugh A, Pelosi F Jr, Jongnarangsin $K$, Latchamsetty $R$ and Armstrong W (2012): Impact of QRS duration of frequent premature ventricular complexes on the development of cardiomyopathy. Heart Rhythm, 9(4): 1460-1466. 


\section{تقييم تأثر وظائف البطين الأيسر الإنقباضي في مرضي

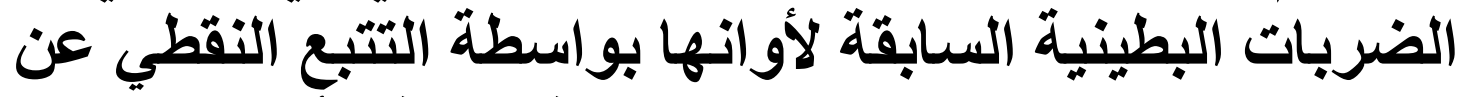 طريث الموجات فوق الصوتية ثلاثية الأبعاد}

أحمد السباعى قاسم، عبدالمحسن مصطفى عبده أبوعاليه***، طاهر سعيد عبد الكريم*؛

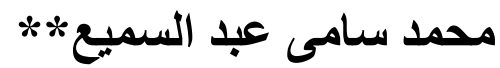

قسم القلب***، كلية الطب، المركز الاسلامى لأمراض القلب*، جامعة الأزهر بالقاهرة

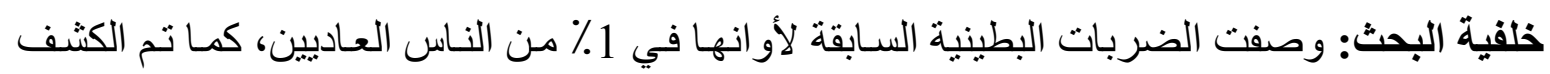

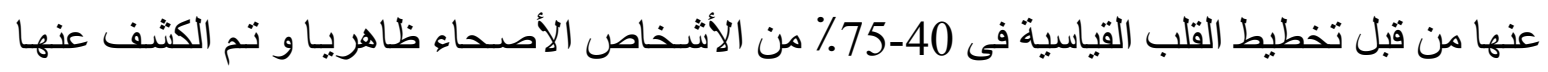

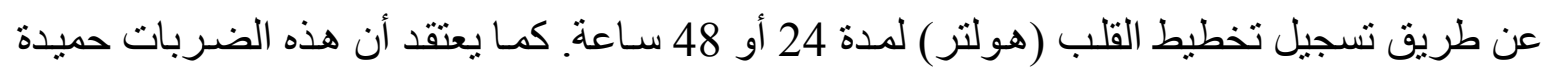

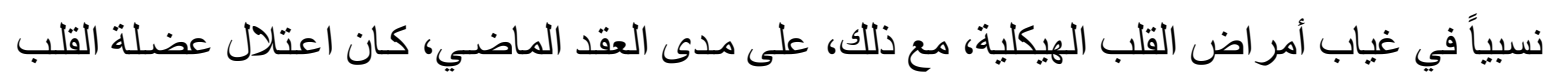

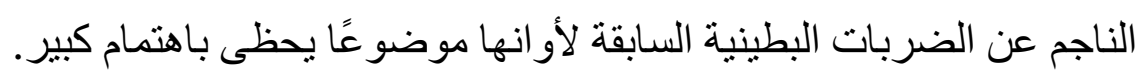

الهـف من البحث: الكثف المكبر وتقيبم إعتلال البطين الأيسر الخفى في المرضى الذين يعانون من

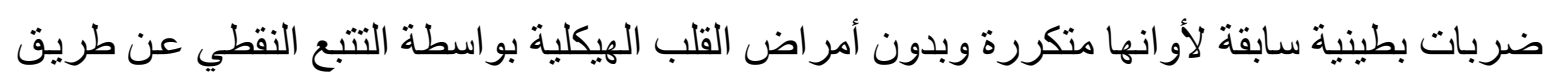
الموجات فوق الصوتية ثلاثية الأبعاد.

المرضس وطرق البحث: تضمن البحث أربعين مريضـاً يعانون من ضـربات بطينيـة سـابقة لأو انها

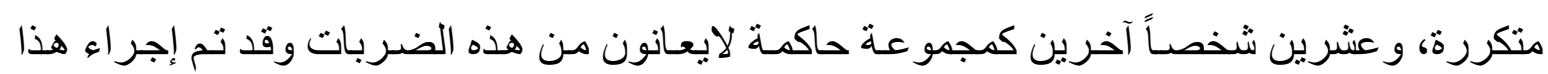

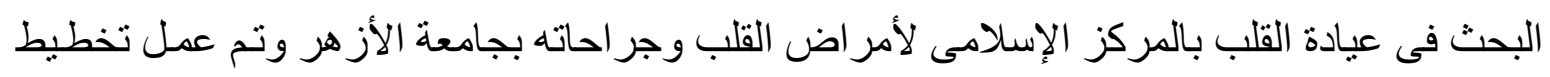

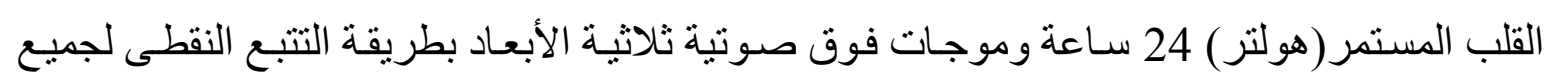

$$
\text { الحالات فى الفترة من سبتمبر } 2019 \text { الى أبريل } 2020 .
$$

نتائج البحث: التتبع النقطى ثلاثى الأبعاد بواسطة الموجات فوق الصوتية قادر على اكتثـاف الاعتلال

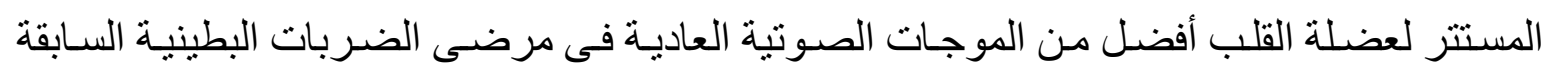
لأو انها، كما أن لهذا الاعتلال علاقة بعددها وأماكن نشو ائها وخصائصها.

الإستتتاج: الضربات البطينية السابقة لأوانها من المكن أن تؤدى إلى إعنلال مستتر فى عضلة القلب،

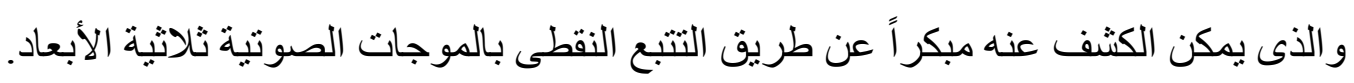

